QUADERNS DE FILOSOFIA VOL. VII NÚM. 2 (2020): I 43 -I 70

eISSN: 234 I-3042 DOI: I O.7203/QFIA. 7.2.I 8804

Elisabetta di Minico

IULM, Milà

\title{
Entre el malson i la realitat. Reflexions distòpiques sobre la societat contemporània
}

Between Nightmare and Reality: Dystopian Reflections on the Contemporary Society

Resum: Per mitjà de la narració de fantasia i de ciència ficció, la utopia i la distopia promouen una anàlisi crítica de la realitat. En particular, la distopia ens alerta de les possibles conseqüències catastròfiques derivades de problemes sociopolítics existents i contribueixa la reflexió constructiva sobre les amenaces antidemocràtiques que posen en perill la nostra societat. Aquest article examina la representació de I'autoritat, la coacció, la propaganda, la plasmació, I'espai i el llenguatge en distopies sociopolítiques seleccionades i reconegudes, com Nosaltres de Zamiatin, Un món feliç de Huxley, La nit de l'esvàstica de Burdekin, 1984 d'Orwell i El conte de la serventa de Atwood, i compara aquestes ficcions amb esdeveniments històrics i contemporanis, amb l'esperança d'il.luminar la manera real en què el poder opera sobre els cossos i les ments en sistemes tant repressius com liberals.

Abstract: Through fantasy and science fiction storytelling, utopia and dystopia promote a critical analysis of reality. In particular, dystopia warns against the possible nightmarish consequences of factual socio-political issues, as well as it fosters a constructive and thought-provoking reflection on the undemocratic threats that jeopardize our society. This article examines the representation of authority, coercion, propaganda, embodiment, space, and language in selected and renowned socio-political dystopias, including Zamyatin's We, Huxley's Brave New World, Burdekin's Swastika Night, Orwell's 1984, and Atwood's The Handmaid's Tale, and it subsequently compares these fictional depictions with historical and contemporary events, hoping to shed light on the real way that power operates on bodies and minds both in repressive and liberal systems.

Paraules clau: distopia, utopia, control, violència, realització.

Keywords: dystopia, Utopia, Control, Violence, Embodiment. 
$\mathrm{D}$ ES DEL PRINCIPI DELS TEMPS, homes i dones han contat sempre històries i hi han confiat importants significats sociopolítics: des del folklore fins a la literatura i el cinema, la cultura és capaç de "promoure el desenvolupament i el creixement humà de la societat" (Panattoni 2002, 122). Aquest "valor eticocognitiu" (Ibid., 122) no és exclusiu de la descripció d'allò real, sorgeix també a través de la narració fantàstica, com les visions utòpiques i distòpiques de mons distants en el temps i/o en l'espai.

La utopia és un gènere que descriu una forma de govern ideal, sovint oposada a les realitats on viuen els autors. Encara que es va desenvolupar plenament en el segle Xvi, la creació d'una societat perfecta és inherent a la història humana i té les seues arrels en la mitologia, la filosofia i la religió. Poden, de fet, ser considerats protoutòpics els mites auris o edènics, que descriuen temps o llocs immaculats, pacífics i pròspers, on els homes no envelleixen, no emmalalteixen o no moren, com al Jardí de l'Edén o durant l'Edat d'Or grega, i els mites religiosos que esperen un regne, material o espiritual, de beatitud i rectitud després de la mort o després de la fi dels temps, com el Paradís cristià o islàmic, els Camps Elisis, les Illes Afortunades, el Valhalla i d'altres. Nombrosos mites estan connectats amb la geografia i contemplen realitats felices i justes amagades en zones remotes o fantàstiques, moltes vegades accessibles a través de viatges iniciàtics, com les illes màgiques de Thule, l'Atlàntida o Avalon. Encara que el primer projecte utòpic ante litteram es troba en l'obra de Plató, la República, tractat dialògic escrit entre el 390 i 360 aC que descriu una forma racionalment ideal de ciutat, governada per reis-filòsofs, la utopia va nàixer oficialment en 1516, amb Thomas More. L'escriptor anglés va crear el gènere amb el seu Libellus vere aureus, nec minus salutaris quam festivus de optimo rei publicae statu, deque nova insula Utopia. Habitualment sintetitzada com Utopia, l'obra descriu la pacífica i idíl.lica illa d'Utopia, descoberta per l'explorador Raphael. More va encunyar també el terme, que deriva del grec antic i se situa a meitat camí entre dos significats: la utopia pot ser un "bon

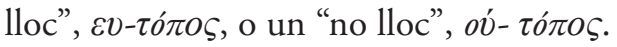

La solució utòpica de mesclar narrativa i disquisició filosòfica va resultar profundament original i reeixida, ja que va augmentar la difusió de conceptes doctrinals i didàctics i va arribar a un nombre cada vegada major de lectors. Aquest gènere, que inclou obres notables com La ciutat del sol (1602) de l'italià Tommaso Campanella i La Nova Atlàntida (i627) de l'anglés Francis Bacon, afavoreix un lent però tenaç debat cultural i científic sobre la societat. La profunda fe humanista en el poder de la raó va impulsar la cerca de solucions de govern equitatives i desenvolupades i la certesa que la fundació de la ciutat 
ideal depenia exclusivament de l'home. La utopia va fer d'aquesta ciutat ideal el centre de la seua reflexió i, encara que fora d'inspiració vagament cristiana, va secularitzar les promeses de pau, igualtat i prosperitat que la religió lliura al Paradís. A partir del segle XviII, el gènere es va sumar a programes polítics $\mathrm{i}$ va promoure canvis que no eren només teòrics, sinó reals, que eixien dels seus límits literaris i filosòfics. La Il-lustració, la Revolució Francesa, la Revolució Industrial, el Socialisme Utòpic, ${ }^{1}$ per exemple, van ser moviments impulsats per aspiracions utòpiques i van secundar, malgrat les diferències entre aquests, el progrés humà i social, els drets universals i naturals dels ciutadans i el millorament de les condicions de vida de la població.

No obstant això, a aquesta cerca de la societat perfecta va començar a oposar-s'hi, a poc a poc, una visió pessimista del futur: les promeses incomplides de les revolucions europees i americanes en els segles XVIII i XIX, incloses la crisi de valors i les violències del Terror francés, mes l'impacte alienador del progrés industrial i del capitalisme van mostrar el costat fosc de la utopia, amb la seua falta de drets, injustícies, pobresa, lluita de classes, esclavitud, colonialisme i imperialisme. La fe dogmàtica en el desenvolupament imparable i en la constant millora social, política i econòmica es va trencar i va causar la crisi de la utopia. La cultura, encara que desitjant sempre el "bon lloc", va començar a témer-ne el dolent. Ja des del segle XIx, molts intel-lectuals, en lloc de proposar models utòpics, van començar a observar, amb desil-lusió i por, errors, abusos i perills socials. En aquest context, $s^{\prime}$ hi troba una obra literària fonamental, tant per a la narració utòpica com per al desenvolupament de la distopia: Notícies d'enlloc (1890), del britànic William Morris. La novel.la conta la història de William Guest, que s'adorm en l'època de la Revolució Industrial i desperta en el futur, al Londres de l'any 2000, on reina una feliç utopia anarquista i agrícola. Aquesta obra sentimental i socialista va traçar el principi de la fi de la utopia: el "bon lloc", ara, només és un anhel. Ja no és un espai físic, sinó oníric. El desencantament de Morris va anticipar els deliris de la distopia, que va començar a triomfar, precisament, a la fi del segle XIX.

Un dels primers autors distòpics, així com un dels pares de la ciènciaficció, va ser el britànic $\mathrm{H}$. G. Wells, que, a més d'utopies, va descriure futurs infernals. En La màquina del temps (I895), per exemple, narra una lluita de

${ }^{1}$ En el segle XIX, els primers corrents socialistes van revelar una forta influència utòpica. En els pensaments d'exponents com Robert Owen o Henri de Saint-Simon, les demandes polítiques i sindicals i les doctrines econòmiques es van unir a programes d'inspiració utòpica. L'anglés Owen, per exemple, va adquirir en 1800 el poblet escocés de New Lanark i les fabriques de cotó adjacents per a convertir l'àrea en una fabrica-comunitat experimental socialista, on el treball infantil estava prohibit, els salaris i les condicions de vida eren decents, i l'atenció mèdica per a treballadors i famílies era gratuïta. Es van obrir també una escola, una guarderia, i l'Institut per a la Formació del Caràcter, per a classes nocturnes, teatres, i concerts. 
classes tan extrema i dilatada, desenvolupada durant diversos mil.lennis, que burgesos i proletaris, incapaços de resoldre aquesta lluita, s'han transformant en éssers deformes i repugnants. Des de Wells, les obres que profetitzen futurs foscos i dramàtics van augmentar de manera exponencial. Van ser i són expressions de la història dels segles Xx i XXI, escenaris de guerres mundials, dictadures, terrorismes, persecucions, genocidis, violacions massives, contaminació, bombes atòmiques i d'altres aberracions.

De les cendres del "bon lloc", en va sorgir la distopia (grec antic $\delta v \sigma$ -

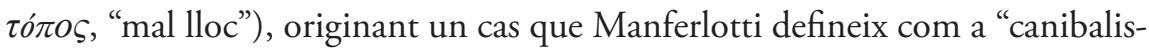
me literari” ( 1984,39$)$. La distopia, que va començar a difondre's massivament des de la primera dècada de 1900, es mou generalment en contextos futurs i de ciència-ficció, proposant emfaticament versions extremes i impactants dels riscos moderns. El primer temor, encara actual, al.ludeix a la industrialització: el progrés revolucionari es converteix en una espiral descendent que origina societats dominades per les màquines, amb humans deshumanitzats i criatures mecàniques humanitzades, amb fabriques i ciutats transformades en paranys laberíntics i monstruosos. El gènere parla també dels desastres científics i ecològics, de mons postapocalíptics, de la superpoblació i la hiperurbanització, de ciutadans manipulats per les corporacions, el consumisme i la publicitat, de teatralitzades dictadures violentes i repressives.

Tradicionalment, se suposa que el primer a encunyar el terme "distopia" va ser John Stuart Mill en 1868, durant un discurs en la Cambra dels Comuns. En la seua intervenció parlamentària, el filòsof, polític i economista anglés va atacar els seus oponents titlant-los de "distòpics o cacotòpics" perquè "allò que comunament es diu utòpic és quelcom massa bo per a ser practicable, però allò que ells semblen afavorir és massa dolent per a ser factible" (KUMAR I99I, 447). Sovint, la distopia, també dita antiutopia, ${ }^{2}$ és considerada com l'"ombra" (Ibid., 99) de la utopia perquè generalment construeix llocs resultants de la degeneració dels projectes utòpics. Mentre que la utopia "avança o anticipa el millor dels mons possibles o pensables per als humans [...] i ho fa enllaçant quasi sempre el bon temps passat (idealitzat) amb l'extrapolació cap al futur de trets o característiques (del passat o del present) que es consideren positius" (FerNÁNDEZ BueY 2007, 217), la distopia mostra "els abusos potencials que podrien resultar de la institució d'alternatives suposadament utòpiques" (Booker I994, 3) i crida "l'atenció sobre alguna cosa que l'utopista tendeix a ignorar o passar per alt: l'efecte pervers que per als humans té la idealització d’allò que

${ }^{2}$ Existeixen també unes altres paraules menys difoses però igualment interessants per a definir el "mal lloc", com pseudoutopia, utopia negativa, contrautopia i cacotopia. Aquesta última, per exemple, va ser inventada en 1818 pel filòsof i jurista anglés, pare de l'utilitarisme, Jeremy Benthan, que també va ser el creador del panòptic, una presó ideal i "transparent", arquetip de control distòpic. 
anomenem progrés o desenvolupament, ja siga en l'àmbit cientificotècnic o en el pla politicosocial" (Fernández Buey 2007, 218). Segons Kumar (I99i), que sembla preferir el terme "antiutopia" a "distopia", "la utopia i l'antiutopia són antitètiques però interdependents. [...] L'antiutopia està formada per la utopia, i s’alimenta parasitàriament d'aquesta. [...] És la imatge especular de la utopia, però una imatge distorsionada, vista en un espill trencat" (100).

Segons crítics com Sargent i Battaglia, existeix una diferència crucial entre la distopia i l'antiutopia: mentre la distopia representa els "mals llocs" d'una manera més complexa i àmplia (BatTaglia I 998, 9), l'antiutopia fa referència a aquelles obres obertament "dirigides contra la utopia i el pensament utòpic" (SARGEnT I975, 138). D'acord amb aquesta visió, 1984 de George Orwell seria totalment una distopia, mentre que la distopia d'Un món feliç d'Aldous Huxley, on el mal lloc resulta de la corrupció dels plans utòpics que volien garantir, en principi, la felicitat i la prosperitat per a tota la societat, revelaria una forta càrrega antiutòpica.

Siga o no siga una "resposta negativa" a la utopia (Kumar I99I, 100), el detall més rellevant de la distopia és que encarna "una crítica de les condicions socials o dels sistemes polítics existents" (BooKer I994, 3), representant paròdicament les relacions de poder de les societats contemporànies i cridant "l'atenció sobre un mal incoat en el present, la realització del qual vol evitar l'autor de la distopia corresponent" (Fernández Buey 2007, 218). Baccolini i Moylan (2003) també subratllen la poderosa crítica social de la distopia i la seua invitació a resistir contra diferents formes de poders discriminants: "l'ordre oficial i hegemònic de la majoria de les distopies [...] depén, com diu Antonio Gramsci, tant de la coerció com del consentiment" (5), i construeix el cos públic i privat de la societat a través de mecanismes que van de la por, la violència i el dolor a la propaganda, el sentit de pertinença i les necessitats adulterades que exalten el plaer, el materialisme i la comoditat. Les persones es converteixen en "terres" per envair i conquerir. Moltes obres, des de Nosaltres fins a 1984 , des d'Un món feliç fins a $V$ de Vendetta, estan unides pel fet que descriuen escenaris on el control social, polític i cultural de la població és l'argument central de la trama.

\section{Poder i COerció en NOSALTRES, UN MÓN FELIÇ I 1984}

Les societats descrites en la majoria de les distopies són jeràrquiques. El govern es troba encarnat per un líder fort i carismàtic al voltant del qual es desenvolupen la ideolatria i la sacralització de la política. La població, per part seua, ha de mostrar i celebrar constantment la seua afiliació al poder, i es troba 
manipulada a través de la propaganda, l'educació i els mitjans de comunicació, vigilada constantment per organismes governamentals, policies secretes i simples ciutadans. El resultat és l'abolició de la intimitat a favor d'una supervisió constant. El sistema polític imaginat per moltes distopies ensenya que la individualitat és negativa, que allò correcte consisteix a unir-se al conformisme dominant. L'autoritat esclafa l'ego, les emocions, la privacitat, l'idealisme i les capacitats crítiques dels ciutadans per a evitar la formació de dissidents. La submissió plena dels habitants es pot obtindre amb diversos graus de violència, que van des de la manipulació i el condicionament a través d'un plaer forçat i/o un ordre categòric, com en Nosaltres o Un món feliç, fins a l'eliminació psicofísica dels subjectes, com en 1984.

Nosaltres va ser escrita entre 1919 i 1921 (i publicada en 1924 en anglés) pel rus Ievgueni Zamiatin, intel.lectual que va donar suport a la revolució bolxevic i va patir la censura i l'exili, primer de mans tsaristes, després pel nou govern comunista. El seu imaginari Estat Únic està estrictament organitzat i mecanitzat, fins al punt de considerar els habitants com a simples números. Els noms, de fet, es componen amb impersonals codis de lletres i xifres (el protagonista, per exemple, s'anomena D-503). Oblidades l'entropia i la irracionalitat dels temps passats, aquesta nova societat gira al voltant d'una "felicitat matemàticament exacta" (ZAMiATin 2007, 37). La vida quotidiana depén de la Taula de la Llei, que determina minuciosament l'horari i les accions dels ciutadans. L'equilibri social brolla de la transformació de l'ésser humà en una màquina regulada per ritmes rigorosament prefixats:

Cada matí, amb la precisió de sis rodes, nosaltres, milions, ens alcem a l'uníson, a la mateixa hora i en el mateix instant. Milions comencem i acabem de treballar a l'uníson, a la mateixa hora. I, fusionant-nos en un únic cos de milions de mans, en l'instant designat per les Taules de la Llei, ens emportem la cullera a la boca, al mateix temps eixim a passejar [...], i ens n'anem al llit (Zamiatin 2007, 13)

L'obra critica tant el capitalisme i el taylorisme, que fabriquen industrialment homes idèntics i inconscients, degradant $\mathrm{i}$ alienant els treballadors, com el comunisme soviètic, que nega la individualitat i la llibertat. Zamiatin concebia la igualtat com una obsessió monstruosa i panòptica que sacrifica la consciència i la sensibilitat en nom de l'Estat i del progrés. Morta la humanitat, moren amb ella l'art, la poesia, i la literatura, el privilegi a l'autodeterminació i l'elecció. La llibertat du a la contestació, a la privació i a la lluita, mentre que la felicitat es pot trobar facilment a través de la renúncia a la lliure voluntat. 
Un món feliç, novel.la de 1932 signada per Aldous Huxley, també parla d'una societat manipulada en nom de la felicitat. L'Estat Mundial dirigeix una estructura econòmica col-lectivista i jeràrquica, composta per una població dividida en cinc castes i vehiculada per una ideologia hedonista, promíscua i desentimentalitzada. La producció en massa s’aplica a la pròpia reproducció humana: la maternitat va ser abolida i els xiquets es creen en laboratoris. Sobre la base del principi de kalokaghatia descendent, els membres de les classes altes, Alfa i Beta, es dissenyen per a ser intel-lectualment avançats i estèticament atractius, mentre que els de les classes més baixes, Gamma, Delta i Ėpsilon, són dissenyats per a ser físicament deformes i mentalment limitats. Però la biologia no és suficient per a modelar els ciutadans perfectes. Durant el creixement, els xiquets són condicionats per a realitzar únicament les tasques pròpies de la seua casta, acceptar la seua predestinació i participar del consumisme, gràcies a la hipnopèdia i els principis pavlovians. El control violent i explícit s'exclou en la civilització concebuda per Huxley, un espai aparentment liberal, festiu i infantil on la coerció s'exerceix inconscientment per un mateix i la conformitat ve programada des de la infantesa, donant lloc a una repressió invisible, com a màxim amable. En canvi, 1984, obra de George Orwell escrita en 1948, mostra un poder brutal, invasiu, despietat, fundat sobre el bel-licisme, la propaganda i els mitjans de comunicació, l'ús constant de la por i l'odi. El líder màxim d'Oceania és el Gran Germà, essència del control. "El Gran Germà et vigila" recorda a la població que el poder ho pot veure tot i que les persones són propietat del govern, sense drets ni privacitat. Tots els apartaments estan equipats amb una pantalla que, a més de transmetre programes propagandístics, registra tot allò que succeeix en el seu camp visual. "La pantalla es converteix en una espècie de paròdia religiosa de l'ull de Déu, que està sempre present i et veu en tot moment: l'ull, a partir d'una metàfora que subratllava un principi diví i moral, es transforma en una màquina de control social" (Соцомво 1987, 52-3).

La distopia d'Oceania no deriva d'un intent fallit de millorar la societat. És un infern que ja va ser creat com a tal, "l'expressió acomplida de les pors humanes" (ARCIERo 2005, 402). Aquest procés va començar amb un acte fonamental: la destrucció de la història, enemiga de tots els règims distòpics. El passat d'Oceania es troba tan destrossat que no és possible establir què va succeir realment i què és un simple joc de la propaganda.

Si el Partit podia allargar la mà cap al passat i dir que aquest o aquell esdeveniment mai havia ocorregut, això resultava molt més horrible que la tortura i la mort. [...] I si tots els altres acceptaven la mentida que va imposar el Partit, si tots els testimoniatges deien la mateixa cosa, aleshores la mentida passava a la Història i es convertia en veritat (ORWELL 2020, 43) 
La major tragèdia d'Oceania és la total dissolució de l'esperança: no existeix cap possibilitat de revolució. El mateix poder és qui produeix la dissidència, per a després exterminar-la. La disciplina arriba tan lluny que per a ser catalogat com a opositor i eliminat ni tan sols és necessari cometre un delicte: n'hi ha prou amb pensar-hi, perquè "ortodòxia significa no pensar, no necessitar el pensament" (ORWell 2020, 61). Amb un joc pervers, el partit espenta els ciutadans a desitjar canvis i a experimentar sentiments prohibits, per a després castigar-los, buidar-los d'ideals i remodelar-los. Arrestat i torturat, Winston comprén el "com" de l'autoritat absoluta, però no el "per què", i li demana explicacions al seu botxí O’Brien. La resposta és aterridora, i la tragèdia d'Oceania, amb la seua estructura clàssica, no pot acabar d'altra manera més que sense guanyadors i sense il.lusions:

El Partit vol tindre el poder per amor al poder mateix. No ens interessa el benestar de la resta; només ens interessa el poder. Ni la riquesa ni el luxe, ni la longevitat ni la felicitat; només el poder, el poder pur. [...] El poder no és un mitjà, sinó un fi en si mateix. No s'estableix una dictadura per a salvaguardar una revolució; es fa la revolució per a establir una dictadura. L’objecte de la persecució no és més que la persecució mateixa. La tortura només té com a finalitat la mateixa tortura. I l'objecte del poder no és més que el poder. Comences a entendre'm? (ORWELl 2020, 259)

\section{ELS COSSOS DE LA DISTOPIA}

Els protagonistes dels "mals llocs", usualment homes fins fa pocs anys, són presentats inicialment com a personatges buits, condicionats i domesticats. Viuen una vida controlada i desentimentalitzada, mancada de lliure albir. En abundants obres, es troben tan alienats que se senten feliços de la seua esclavitud. Estranya mescla entre herois i antiherois, al final, tanmateix, arriben a un (de vegades inútil) acte de rebel-lió. En general, l'afectivitat i/o la sexualitat juguen un paper alliberador i adquireixen el rol d'accions rebels i transgressores que afavoreixen l'emancipació dels protagonistes, l'obertura de canals de comunicació i sentimentalitat en mons on l'una i l'altra estan prohibides o desaconsellades. Per aquest motiu, les insurreccions contra el poder es vinculen sovint amb una dona. En la majoria de les distopies amb protagonistes masculins, sempre hi ha una figura femenina de referència que simbolitza l'amor, encara que no necessàriament físic, sinó també romàntic, filial o maternal. Les dones provoquen el despertar, la desalienació, activen la resistència i la desobediència dels protagonistes. El paper atribuït a la 
dona per la distopia evoca a la funció salvadora i inspiradora que Beatriu representava per a Dante en la Divina Comèdia (I 304-I 32I). En les obres amb protagonistes femenines o amb temes centrats en qüestions de gènere, el poder distòpic es mostra com una autoritat fortament patriarcal, capaç de violar psicofísicament, aïllar i mercantilitzar els cossos de les dones. Les herö̈nes d'aquestes històries són víctimes per partida doble, i han d'enfrontar-se no sols als poders sociopolítics, sinó també a una opressiva violència masculina.

Addicte al benestar o transfigurat pel dolor, normalitzat en qualsevol cas, el cos compta amb un gran protagonisme en el gènere distòpic perquè, segons va advertir Foucault, és la matèria de l'autoritat, el camp sobre el qual "es promulguen i exerceixen les relacions de poder, les estructures socials i la política” (INDERBITZIN et al. 20 I 2, 73). Els poders imaginats per la distopia construeixen i destrueixen els ciutadans per a garantir-se protecció, privilegis i força. L'autoritat necessita cossos "útils i dòcils" (Foucault I993, 251) que facen costat al govern, li garantisquen força laboral i bèlllica i tinguen valor econòmic. Per això, imposa un massiu i impecable control mèdic, sexual, espacial i cultural sobre ells.

Els cossos rebels i diferents, no submisos, no fèrtils, no productius, es converteixen així en elements a esclafar, tant per una qüestió d'estabilitat com per raons propagandístiques i ideològiques. Carl Schmitt va sostindre que la presència d'un enemic és necessària per a la construcció social i jurídica del poder. Els enemics interns i externs representen una "alteritat" antitètica que s'oposa conceptualment i activament a l'ordre consuetudinari, amenaçant l'ordre i la seguretat. Segons Hannah Arendt (1962), els enemics ni tan sols necessiten rebutjar els ideals comuns o tractar d'enderrocar el govern: els enemics són simplement "portadors de tendències" que les autoritats poden transformar en objectius adequats i plausibles de repressió i control (423-4).

El Gran Germà d'Orwell sotmet i mortifica el cos dels seus ciutadans mitjançant la por constant, de l'odi a l'enemic intern i extern requerit com a prova d'obediència, de la demonització de la sexualitat i de l'afectivitat. A canvi, obté el plaer inferit de la repressió i la destrucció dels cossos rebels: "El poder radica a infligir dolor i humiliació. El poder està en la facultat d'esbocinar els esperits i tornar-los a construir donant-los noves formes triades per tu”, afirma O’Brien (Orwell 2020, 271). El sistema veu en Winston un feble, reconeix en ell els símptomes de la dissidència i l'acompanya en la desobediència, només per a destruir-lo i convertir-lo en una no-persona condemnada a la damnatio memoriae. El fa caure, el converteix, i aconsegueix la seua cega lleialtat en convéncer-lo que $2+2=5$. Al final, decideix matar-lo, tot just quan Winston estima de cor el Gran Germà i odia els no conformes. 
Amor i erotisme són pecats imperdonables a Oceania perquè l'afectivitat i la intimitat allunyen els ciutadans de l'obediència cega i la submissió a l'ortodòxia. La seua repressió contribueix a crear subjectes neuròtics, disciplinats i influenciables, i afavoreix el control sociopolític. Tots s'espien entre si, $i$ en cas de (vertader o suposat) delicte denuncien l'altre sense remordiments. Quan Winston i Júlia inicien la seua relació, el sexe es transforma en un acte d'autoafirmació, de reapropiació dels seus cossos retinguts i de revolta contra la puritana biopolítica d'Oceania. Després de ser torturats per la Policia del Pensament, tots dos acaben emotivament esterilitzats, desproveïts d'instints i emocions, i detesten el desig carnal que sentien l'un cap a l'altre.

Un altre exemple de massacre psicofísica dels cossos dissidents, aquesta vegada des d'una perspectiva feminista, és La nit de l'esvàstica, novel.la del 1937 escrita per Katharine Burdekin. Anys abans del dramàtic esclat de la Segona Guerra Mundial, l'obra imagina un futur on el nazisme domina despietadament el món, i imposa opressió i discriminació racial, religiosa i de gènere. A Hitlerdom, els cossos discordants o ja no existeixen, com el poble jueu que va ser exterminat, o han sigut totalment demacrats, com els cristians i les dones. Aquestes últimes, de fet, representen la part més abusada de la població: físicament embrutides i rapades, confinades en espais especials, obligades a caminar corbades per a no ofendre els homes, privades de bellesa i coneixement, es redueixen a un ramat obedient. La societat patriarcal i violenta de la novel.la "està connectada directament amb el nazisme i la guerra", mostrats com a principis masculins que destrueixen per complet els principis femenins i les dones mateixes (McKay 1996, 195).

De manera similar, El conte de la serventa (1985) de Margaret Atwood descriu la brutal dictadura de Gilead (versió teocràtica i feixista dels Estats Units), distopia patriarcal basada en el fonamentalisme religiós. Encara que tots dos sexes estiguen privats de llibertats, les dones són les qui pateixen, amb molta diferència, la major deshumanització: òrfenes de drets, es converteixen en objectes de propietat dels homes, en mercaderia distribuïda en grups fixos, diferenciables pels seus rols i color de roba. Les esposes, per exemple, visten de verd-blau, les marthas (serventes) de gris i les criades de roig. Aquestes últimes són dones ferrtils triades com a mares substitutes per les elits de Gilead. Esclaves sexuals regularment violades pels Comandants (mentre les seues dones assisteixen a les agressions presentades com a rituals religiosos), estan obligades a gestar i després deixar els seus fills als seus "amos". Considerades com a béns materials, perden els seus noms originals i es converteixen en complement: la protagonista, propietat de Fred Waterford, és rebatejada com Defred.

Defred intenta resistir-se a l'autoritat, lluitant mentalment per a continuar sent un subjecte actiu i no un objecte passiu. Dia rere dia, el seu cos deixa de pertànyer-li i de respondre a la seua voluntat. 
Gilead la buida i la converteix en un "úter amb cames".

Acostumava a pensar en el meu cos com en un instrument de plaer, o un mitjà de transport, o un utensili per al compliment de la meua voluntat. [...] Existien límits, però tot i això el meu cos era àgil, únic, sòlid, formava una unitat amb mi. Ara el cos se les arregla per si mateix d'una manera diferent. Soc un núvol solidificat al voltant d'un objecte central, en forma de pera, que és dur i més real que jo i brilla en tota la seua rojor envoltat per un embolcall translúcid. Dins hi ha un espai immens, fosc i corb com el cel nocturn, però roig en lloc de negre (ATwOOD 2007, 115)

El poder assalta així íntimament la carn dels personatges i es converteix en un element intern d'aquests. $V$ de Vendetta, sèrie de còmics dels anys huitanta escrita per Alan Moore i il.lustrada per David Lloyd, insisteix en tal intrusió. L'obra presenta un Regne Unit regit pel partit feixista Foc Nòrdic, formació que cancel.la els drets civils i elimina minories i opositors mitjançant l'ús dissuasiu de la por, la vigilància i la força. Titllats d'indesitjables, V i Valerie, una actriu lesbiana, acaben tancats en camps de concentració. El poder priva Valerie de la seua imatge, individualitat i feminitat: utilitzada per a l'experimentació científica, el seu cos és picat, tallat i massacrat abans de ser liquidat. Ara bé, l'assassinat no és el fi últim de la violència distòpica, sinó la deshumanització de les víctimes, la destrucció de les identitats i corporalitats considerades corruptes. En la distopia, la desobediència transcendeix la categoria de crim i es converteix en una malaltia social, igual que els cossos rebels es converteixen en tumors que cal extirpar del cos social.

Els règims de poder de la distopia no manipulen i cosifiquen els cossos individuals sols a través del control "negatiu" o victorià, típic de la repressió, la tortura i l'assassinat. Tal com he insinuat abans, actua, d'igual manera, a través d'un control "positiu" que busca persuadir i entabanar abans que castigar i violentar, que busca l'empatia dels súbdits abans que la por. En Un món feliç, el control és més positiu en aquest sentit, i els cossos dels protagonistes gaudeixen de plaer i benestar permanent. Plaer, amb tot, que no representa cap acte d'alliberament emocional i sensual, sinó una expressió més de l'obediència i la servitud. Un altre exemple d'aquesta tendència a controlar els individus a través de la diversió és La fugida de Logan (1976), pel-lícula de Michael Anderson basada en la novel.la homònima de William F. Nolan i George Clayton Johnson. En 2274, la Terra postapocalíptica, per a evitar la sobrepoblació, mata els seus ciutadans als 30 anys, després d'atordir-los amb luxe, relax, benestar i entreteniment. Abans de "desaparéixer" durant la cerimònia del Carrusel, de fet, tots viuen una vida feliç i ociosa, perfecta 
actualització de la famosa i demagògica locució llatina panem et circenses. En els mons del control positiu, aplicant la crítica marcusiana a la distopia, "el 'principi de plaer' absorbeix el 'principi de realitat”" (Marcuse 1993, 102):

El grau de satisfacció socialment permissible i desitjable s'amplia granment, però mitjançant aquesta satisfacció el principi de plaer és reduït en privar-s'hi de les exigències que són irreconciliables amb la societat establida. El plaer, adaptat d'aquesta manera, genera submissió (Ibid., 104)

\section{LeS VEUS SENSE VEUS DE LA DISTOPIA}

Per a arribar a actuar de manera indiscriminada sobre el cos social i personal, el poder distòpic manipula el llenguatge i desplega un discurs públic basat en la por i l'odi. Una característica fonamental de 1984, per exemple, és la instrumentalització de la llengua, mètode dirigit a originar una degeneració sintàctica i conceptual. La novaparla d'Oceania és un idioma artificial simplificat, creat pel partit amb la finalitat d'aniquilar els processos cognitius i la formació del pensament dels parlants, per a facilitar el condicionament de la col-lectivitat. Al mateix temps, la novaparla estimula un procés anomenat "doblepensar" gràcies al qual és possible afirmar al mateix temps fets contradictoris i impossible distingir la veritat de la mentida. A Oceania, "la guerra és la pau, la llibertat és l'esclavitud, la ignorància és la força". Quan el partit postula que $2+2=5$, el ciutadà integrat de 1984 deixa de creure en les matemàtiques i s'abandona a l'ortodòxia cega dels que governen.

De manera similar, en El conte de la serventa el llenguatge difon missatges patriarcals i justifica l'opressió de les dones a través de la repetició de conceptes misògins i de la banalització del discurs social. Utilitzant una sàdica moral de devoció i sacrifici formulada específicament per a la propaganda, el règim explota la fe com a pretext per a justificar lleis repressives, vigilància $\mathrm{i}$ discriminació, i imposa una versió retorçada de la Bíblia on "les paraules són corrompudes, pervertides o presentades fora de context per a establir una visió sagrada d'un home sobre les dones" (GoldblatT I 999, 279). Lidioma de Gilead és orwel-lià: els "Salvaments" són penes de mort, les "Cerimònies" són violacions institucionalitzades, i així successivament. Els discursos diaris també estan controlats lingüísticament: el llenguatge simplificat i ritualitzat, juntament amb les salutacions estandarditzades, limiten la consciència i dissuadeixen de la crítica. Les frases d'inspiració religiosa "Amb la seua mirada", "Beneït siga el fruit", "i el Senyor permeta que madure", donen suport a l'assimilació d'aquesta nova política basada en el control omnipresent, l'obsessió per la fer- 
tilitat i la sacralització de la violència. Noms i títols d'origen bíblic, enforteixen la sacralització de la societat, convertint els actes de desobediència sociopolítica en pecats mortals. A més, els noms de pertinença (De-fred, De-glen, etc.) de les dones contribueixen a aniquilar la seua identitat, com els noms-números en Nosaltres. Una de les pitjors paraules de la novel-la és "No-dones": les dones no fèrtils, no explotables sexualment i no obedients passen per un procés no sols de deshumanització, sinó també de desfeminització, des d'un punt de vista lingüístic i pràctic. Si no poden proporcionar deferentment treball domèstic, xiquets o plaer, les dones són considerades béns danyats i pateixen la reclusió en les Colònies, camps de treball contaminats per la radioactivitat.

Vox (20 I 8) de Christina Dalcher explica perfectament les conseqüències distòpiques d'aquesta opressió lingüística imaginant que, en un futur previsible, els EUA reduïsquen les paraules que les dones puguen pronunciar diàriament a 100 (en lloc d'una mitjana de 16.000), llevant-los també llibres, papers, bolígrafs i d'altres estris. Les que superen el límit, pateixen un electroxoc a través d'una polsera que compta el nombre de mots articulats $i$, a poc a poc, desapareixen. La limitació del llenguatge està directament relacionada amb la submissió de l'alteritat i de la feminitat: segons Russell (I991, 38), les dones "no tenen possibilitats de crear els seus propis textos perquè no poden escriure els seus cossos".

Si la por, la violència i el control constants impedeixen la rebel.lió contra l'Estat feixista en $V$ de Vendetta, els mass media hi serveixen de suport. La repetició d'imatges i conceptes a través d'un imprinting quasi "paternal", precaritzen al màxim el llenguatge. L'explotació de tons persuasius, que alternen temes alarmistes i entreteniment lleuger, contribueix a limitar la crítica i la dissidència, fins a forjar una banalització de la realitat que pot crear o destruir la veritat en funció de les necessitats polítiques del moment. Un perfecte exemple d'aquesta tendència és Storm Saxon, sèrie que protagonitza un heroi blanc, masclista i racista que promou prejudicis i estereotips sota la retòrica supremacista i patriarcal. Storm afirma: "Aquests negres carnissers violen les nostres dones, cremen, i arrasen...” (MOORE i Loyd 2006).

Quan el govern de la distopia opta per recórrer a llenguatges més edificants, així ocorre en Nosaltres i Un món feliç, l'enginyeria lingüística difon conceptes com felicitat, benestar, llibertat i consum (tant material com sexual). THX 1138, primer llargmetratge de George Lucas de 1971, descriu un món subterrani capitalista habitat per ciutadans "feliçment" sedats amb drogues. A nivell lingüístic, l'Estat utilitza un to de veu relaxat i un lèxic tranquil.litzador i optimista, malgrat l'evident i violenta contradicció que suposa la realitat. Els policies amb equip antiavalots afirmen "ser presents només per a ajudar" mentre colpegen THX i repeteixen: "Tot anirà bé. Eres a les meues mans. Estic 
ací per a protegir-te. No tens on anar". El condicionament mental d'aquesta societat també s'aconsegueix a través de la televisió i la religió. La fe reforça els dictats de l'autoritat i afavoreix la massificació de la ciutadania. El govern explota rituals religiosos que promouen doctrines que equiparen pecat i transgressió civil. Molt significatiu és "el confessionari", lloc on els creients parlen a la deïtat oficial de l'Estat, OMM 0910 (representada iconogràficament pel Crist beneint, pintat en 1478 pel flamenc Hans Memling). De símbol de penediment i reconciliació, el confessionari s'hi converteix en ull i oïda de l'autoritat, en un fals refugi que recomana obediència, consumisme i felicitat: "Eres un vertader creient, una benedicció de l'estat, una benedicció de les masses. [...] Dóna gràcies pel treball. Treballa dur. Incrementa la producció. Evita accidents i sigues feliç".

\section{LA DISTOPIA EN EL TOTALITARISME}

Les mateixes tècniques propagandístiques i repressives exhibides per les obres distòpiques citades travessen la història contemporània, des de la manipulació del llenguatge i de la història fins a la tortura física i psicològica, des de la submissió de la cultura, de l'art i del lliure pensament fins a l'eliminació dels dissidents i dels cossos considerats perillosos o desviats. Tenint en compte les modalitats de control negatiu i positiu, es poden classificar els poders polítics en dues tipologies: dominants i persuasius. Tals extrems no són excloents $i$, tant en la ficció com en la realitat, poden fusionar-se i dosar-se. Independentment del major o menor grau de tensió administrat, els règims totalitaris i autoritaris pertanyen de manera explícita al primer grup, mentre que les democràcies pertanyen al segon.

Les distopies més fosques, el cas de 1984 i El conte de la serventa, presenten un poder fortament sacralitzat, vinculat a allò que Gentile (2007) denomina "religió política", procés que es remunta a la Primera Guerra Mundial. Després de quatre anys de conflicte, es van comptabilitzar quasi 10 milions de morts, amb un elevat nombre de víctimes civils. Va sorgir, aleshores, el que Mosse anomena el Mite de l'Experiència de la Guerra, que va deïficar la pàtria i els caiguts i va transfigurar la mort en acte regenerador dels estats i les col-lectivitats. Els rituals, de suggestió cristiana, van unificar el cos social i "la multitud desordenada del poble es va convertir, gràcies al misticisme nacional, en un moviment de masses" (Mosse 2007, 26). En països amb greus problemes estructurals com Itàlia i Alemanya, aquest misticisme es va desenvolupar en doctrines i moviments polítics d'extrema dreta que van aprofitar la inestabilitat social per a promoure la creació d'una nova societat, destruint el passat polític 
i els valors de les seues nacions. El feixisme i el nazisme van tindre el seu eix en les masses. Segons Le Bon, les masses són destructives, instintives i suggestionables: "Per separat, [l'home] pot ser un individu culte; en una multitud, és un bàrbar, és a dir, una criatura que actua per instint" (Le Bon 200 I, 19). Immers en el grup, l'individu es converteix en una xifra impersonal, mentre que els líders es mostren com a herois investits per un misticisme messiànic. Els Grans Inquisidors distòpics són simplement versions literàries, més o menys exagerades, de l'autoritat carismàtica descrita per Max Weber. El líder carismàtic és un profeta capaç d'atraure a les masses, de sotmetre-les amb retòrica simplificada i atractiva, d'aconseguir la seua dedicació i fer-les partícips de la seua "missió".

Un altre aspecte real descrit en moltes distopies polítiques és l'obsessió dels Estats totalitaris pel control absolut, omnipresent. La història ens ensenya com els mitjans per a aconseguir-ho han estat molt variats, des de la manipulació de la realitat, la propaganda ininterrompuda i la espectacularització de la política fins a la instauració d'un clima de temor i sospita que utilitza les amenaces del delator invisible i de la tortura per a subjugar als ciutadans potencialment subversius. A fi d'emfatitzar la relació directa entre els líders i les masses, les dictadures històriques s'han basat en la dramatització de les formes polítiques. Mítings, desfilades, cerimònies i inauguracions sempre han jugat un paper unificador que busca transmetre símbols i missatges orientats a la consolidació dels règims, exactament com succeeix en Nosaltres, 1984 i El conte de la serventa, entre d'altres.

El principal agent de la propaganda és, per descomptat, l'idioma, medium fundador de la societat i, per tant, del poder que la controla. La paraula, a més de descriure, designar o narrar, també implica acció. És un canal "performatiu" (Austin i975, 62) que pot canviar el context en el qual es pronuncia. Emocions, creences i accions dels receptors poden ser fortament modificades per l'idioma. Els règims distòpics construeixen, segons vam veure, un llenguatge específic per a la massa. Si, com sosté la hipòtesi de Sapir-Whorf, els processos cognitius dels individus estan relacionats amb l'idioma, si existeix una interdependència entre el pensament i el llenguatge, qui controla el llenguatge es troba en disposició de controlar les ments. L'avantatge d'aquesta estratègia és que permet l'exercici d'un control suau, imperceptible. Igual que en 1984, l'objectiu estreba a eradicar no sols la possibilitat de la resistència, sinó fins i tot el mateix concepte d'aquesta. El model comunicatiu del totalitarisme és la reiteració d'afirmacions simplistes, sentimentalment impactants i sense justificació racional. Eslògans, paraules clau i estereotips enforteixen el procés de persuasió. Disseminats pels mitjans de comunicació, ensenyats a les escoles, afirmats amb arrogància durant els mítings, transmeten de la manera més concisa i immediata les idees i els conceptes del poder, com en el famós lema de Mussolini: "Creure, obeir, combatre". 
Quan l'ars oratoria es combina amb una escenografia impressionant, sorgeix "una totalitat dramàtica" (Mosse 2007, 286) on les persones no sols escolten els discursos o participen en esdeveniments, sinó que viuen una experiència mística que els fa oblidar el significat original de les paraules. En les grans reunions del nazisme, Hitler captava els temors i els desitjos de les masses i insistia en temes estandarditzats, com la grandesa del Volk alemany, el perill representat per jueus i comunistes i la categoria d'"elegit" del poble ari. En aquests contextos, l'emoció preval sobre el raonament, i la multitud es fa còmplice de l'autoritat, ajuda a crear i a donar força a l'acte messiànic. Les distopies també es fan ressò del paper jugat pels mitjans de comunicació, l'educació i la cultura en el reforçament del poder. Premsa, ràdio i televisió sempre han estat essencials en la conformació de l'opinió pública i de la mateixa realitat. Resumint l'anàlisi sobre l'obscurantisme del bloc soviètic que l'escriptor russofrancés Vladimir Volkoff va realitzar en la seua novel.la de 1982 Le Montage, la informació subjecta als interessos del poder, mescla la mentida i la veritat, modifica els contextos, desplaça l'atenció sobre temes menors, tergiversa, exagera i generalitza sense deixar a l'oposició —en el cas que encara existisca- cap opció d'expressar-se. Donada la seua importància, la informació es manté sota control estricte, com demostren les lleis aprovades pels diversos règims totalitaris dirigides a censurar la premsa i crear òrgans per a vigilar la informació, cas del Ministeri de Cultura Popular (1937-1944) del feixisme.

Quan el control persuasiu falla, els poders recorren a la força. El primer pas és la vigilància omnímoda dels ciutadans. Les policies polítiques o secretes, com l'OVRA, la Gestapo, l'OCN o la Txeka van ser dissenyades amb l'objectiu de vigilar, espiar i, arribat el cas, intervindre brutalment. Una vegada que s'han identificat els enemics de l'Estat, la policia procedeix a la punició. Com més poder posseeix l'Estat, més radicals, indiscriminats i arbitraris són els mitjans que adopta. Una manera de legitimar l'eliminació física dels adversaris consisteix a privar-los de drets, com van fer els nazis amb les Lleis de Nuremberg aprovades en 1935. Després, es pot passar a accions més dràstiques. Entre 6 i 7 milions de jueus van morir durant la Segona Guerra Mundial. Segons Courtois, la revolució de Mao va provocar l'assassinat de més de 40 milions de persones i el regnat de Stalin de desenes de milions. Franco va ser responsable de la mort de més de 500.000 persones. Ceauşescu de 60.000. Els quatre anys de dictadura de Pol Pot es van saldar amb dos milions de víctimes.

Quant a la temàtica del cos, és ben sabut que des dels segles XVI i XVII la salut física i moral, la família i la sexualitat van deixar de ser assumptes privats, i van assumir, a partir dels segles XVIII i XIX, un significat polític. El cos 
dels ciutadans va aparéixer de sobte com un element a domesticar, organitzar, disciplinar. Segons Foucault, des del segle Xvir l'Estat no es limita a tindre dret sobre la mort, sinó també sobre la vida de les poblacions. Foucault localitza en la modelització dels cossos "dòcils i útils" (Foucault I993, 251) l'acte fundacional del poder contemporani. Amb l'adveniment del capitalisme, el cos adquireix funcions estratègiques: té valor econòmic, com a productor $\mathrm{i}$ usuari, i biologicodemogràfic. Portat a l'extrem, aquest imaginari va inspirar les teories de superioritat racial, social, sexual i de gènere, pilars de l'obsessió per la "puresa" del Tercer Reich. A través de l'esterilització i/o l'assassinat de malalts mentals, deficients i "degenerats" i la prohibició dels matrimonis mixtos, l'Alemanya nazi va convidar les parelles "dignes" a produir fills. Les polítiques eugenèsiques més discriminatòries i la instrumentalització de la sexualitat escenificades per nombroses distopies també s'han manifestat fora de l'àmbit de la ficció durant el passat recent.

El mateix cal afirmar d'un altre leit motiv distòpic: l'existència, real o no, d'enemics als quals culpabilitzar de tots els mals. L'estigmatització d'aquests individus pot recaure en l'ètnia, nacionalitat, ideologia, religió, classe social o orientació sexual. La seua presència facilita la distinció entre "bons" i "dolents", "nosaltres" i "ells", i augmenta la sensació d'inseguretat i la consegüent necessitat de protecció dels ciutadans. ${ }^{3}$ Lenemic pateix nivells tan intensos de deshumanització i estigmatització, que el seu executor perd les inhibicions i no experimenta cap culpabilitat. Zimbardo parla de "Efecte Llucifer", present, per citar uns pocs casos, en l'extermini nazi, en la ràpida degeneració de l'Experiment de la presó de Stanford ${ }^{4}$ i en les tortures dels presoners tancats a Abu Ghraib per militars estatunidencs. En el context adequat, fins i tot persones ordinàries, sense una manifesta predisposició a la violència, poden consagrar-se a la caça i devastació de l'enemic, paradigma del cos discordant al qual infringir deliberadament dolor, expressió per antonomàsia del poder, demostració màxima del control, experiència inhumana que "destrueix també el llenguatge" (SCARRY I990, 83).

${ }^{3}$ Els enemics del nazisme no van ser només les races inferiors, sinó també els "malalts" d'Alemanya. Des de 1933, més de 300.000 ciutadans que patien malalties "perilloses", com l'esquizofrènia, epilèpsia, ceguesa, sordesa, alcoholisme, "desviacions" sexuals, etc., van ser esterilitzats coercitivament. Entre 1939 i 1941, a través del programa d'eutanàsia anomenat Aktion T-4, es van matar entre 60.000 i 100.000 persones amb discapacitats, problemes o retards mentals, tares físiques o genètiques.

${ }^{4}$ En 1971, el professor Philip Zimbardo de la Universitat de Stanford va organitzar un experiment psicològic sobre la percepció del poder i de les lleis i els possibles mecanismes de desindividuació i violència que es poden originar. Vint-i-quatre voluntaris, sense antecedents penals ni problemes psicològics o psiquiàtrics, van ser reclutats per a interpretar rols de "guàrdies" i "presoners". L'experiment hauria d'haver durat 15 dies, però es va concloure al sisé dia pels abusos sàdics dels guàrdies i la submissió dissociada dels presoners. 


\section{LA CARA DISTÒPICA DE LA DEMOCRÀCIA}

Encara que s'associe principalment amb la crítica al totalitarisme, la distopia qüestiona, d'igual manera, les tendències homogeneïtzadores i autoritàries inscrites en les societats democràtiques, vehiculades a través de l'hedonisme, la publicitat, la moda, el consumisme i l'espectacle. La participació constant de les masses en rituals col-lectius, la propaganda distorsionadora i l'enginyeria lingüística i sociocultural no són una invenció dels règims totalitaris. D’una manera o d'altra, ja operaven als països liberals i democràtics des del segle XIX, quan l'adveniment de la societat industrial va afavorir els moviments de masses i la transformació de la multitud en un agent actiu que havia de ser apaivagat i administrat. Analitzant les previsions distòpiques de Huxley i Orwell en Divertir-se fins a morir, Postman (2005) convé que les potències democràtiques s'assemblen a l'obra del primer. El poder democràtic normalment no és violent. Somriu i fa somriure. El Gran Germà es transforma en un programa televisiu de màxima audiència. Encara que les opinions de Postman siguen perspicaces, crec que existeixen dades que mostren que la realitat actual ocupa un lloc intermedi entre el món de Huxley i el d'Orwell. Des dels atacs gihadistes de l'11 de setembre de 2001, s'ha fet evident que el públic ha d'estar espantat, no sols entretingut i somrient. Bombardejades per notícies aterridores sobre els estrangers, els terroristes i la crisi, les audiències sucumbeixen a la por, sentiment que justifica els discursos repressius a l'alça i la presa de decisions que afecten els drets i les llibertats fonamentals. Aquesta tendència troba suport en el ressorgiment de l'extrema dreta, actor distòpic impulsat per la crisi de 2008, armat amb discursos d'odi i discriminació que justifiquen l'ús de la violència i que reobrin l'imaginari bèl-lic dels "enemics" interns i externs. Marcuse va mostrar, no obstant això, que el mètode de control emprat en les denominades societats obertes no passa per la cancel.lació orwel-liana dels drets i llibertats, sinó per la desactivació huxleyana del desig a aqueixos drets i a aqueixes llibertats i per l'anestèsia plaent de la voluntat crítica. La societat exigeix als seus membres "descansar, divertir-se, comportar-se i consumir d'acord amb els anuncis, estimar i odiar el que uns altres estimen i odien” (MARCUSE I 993, 35), fins a transformar la critica "intel-lectual i emocional" en un "signe de neurosi i impotència” (Ibid., 40). Segons Lippmann (I998, 287-90), la població de les societats avançades recorda a un "ramat desconcertat" i incapaç d'autodeterminar-se, governat per minories especialitzades de tècnics i experts. Es consolida així l'"enginyeria del consentiment" (BernaYs I947), la transformació de la cultura, l'educació, la informació i l'entreteniment en mecanismes del poder polític i econòmic. L'autoritat té "dret a la persuasió" (114) i, sense recórrer a la violència explícita, construeix necessitats, costums i objectius. Segons Chomsky 
(20 I I, 10), la concepció ideal de la democràcia, entesa com la participació dels ciutadans en la res publica, ha sigut reemplaçada per un sistema on el bé comú s'aconsegueix "prohibint al públic la gestió dels seus propis assumptes".

La societat de consum no és aliena a la sacralització i espectacularització de les pràctiques polítiques de les quals parlem en el punt anterior. Tampoc a les cerimònies públiques de caires adoctrinadors. Són habituals la teatralitat i personalització de la política, fins a la transformació dels estadistes en celebritats. Per no parlar de l'ús insistent de tècniques de persuasió psicològica a través de la publicitat i dels mitjans de comunicació, del control governamental de la cultura, de la informació i de l'educació, de l'explotació propagandística dels enemics interns $\mathrm{i}$ externs. Les estratègies de màrqueting compleixen un paper fonamental. El llenguatge i les tècniques científiques dels poders persuasius s'uneixen amb el vigor hipnòtic i sentimental de la religió política. Estadístiques, estudis de mercat, enquestes, entrevistes i anàlisis clíniques serveixen al domini dels individus i de l'opinió pública. Els "persuasius ocults" (PACKARD 2007), científicament organitzats, conquisten l'inconscient amb missatges subliminals i descobreixen els disparadors psicològics que espenten algú a comprar un producte, votar per un candidat o donar suport a una llei. Des d'aquesta perspectiva, no semblen tan de ficció la societat de Maniac, minisèrie de Netflix de 2018, on un Ad Buddy, és a dir un pop-up humà, ofereix constantment publicitat als ciutadans a canvi de diners per a les seues compres, o el món d'Estan vius, pel-lícula de 1988 de John Carpenter, ${ }^{5}$ amb alienígenes conqueridors que hipnotitzen els humans a través de missatges subliminals que conviden a: obey (obeir), consume (consumir), buy (comprar), watch television (veure la televisió), stay asleep (quedar-se adormits), do not question the authority (no qüestionar l'autoritat).

Suposant que les persones no saben el que volen i que no sempre actuen racionalment, el màrqueting comercial i polític intenta desencadenar respostes emocionals automàtiques amb paraules, imatges, colors, sons que complisquen, d'acord amb Packard (2007), les huit "necessitats ocultes" dels éssers humans: seguretat emocional, reafirmació del valor (autoestima, reconeixement, acceptació), gratificació de l'ego, impulsos creatius, amor, sensació de poder, arrels (familiars, socials, nacionals, etc.) i immortalitat (Ibid., 86-94). El resultat del bombardeig de la publicitat que veiem tots els dies produeix la versió democràtica de l'homologació de la societat. Fins i tot si es tria un producte " $x$ " en lloc de " $i$ ", hi subjau el mateix desig de consum. El materialisme es converteix en una necessitat, també psicològica. El capitalisme i el consens no poden ser qüestionats, com en Un món feliç, en Mercaders de l'espai (1953) de

${ }^{5}$ Estan vius (títol original: They Live) està basada en el conte Eight O'Clock in the Morning (1963) de Ray Nelson. 
Frederik Pohl i Cyril M. Kornbluth, on el "somni americà" es torna físicament invasiu i transforma els ciutadans en consumidors esclavitzats, i en $\mathrm{Hell}^{\prime}$ ' Pavement (I955) de Damon Knight, on el consumisme es converteix en religió i on el pecat de la població, hipnotitzada des del naixement, és equivocar-se fent compres. En la nostra societat basada en espectacle, aparença i possessió, la que Marcuse anomena "cultura industrial avançada", la ideologia està fusionada amb el procés de producció i fa distòpicament impossible qualsevol forma de resistència.

L'aparell productiu, i els béns i serveis que produeix, «venen» o imposen el sistema social com un tot. Els mitjans de transport i comunicació de masses, els béns d'habitatge, alimentació i vestuari, l'irresistible rendiment de la indústria de les diversions i de la informació, comporten hàbits i actituds prescrites, unes determinades reaccions emocionals i intel.lectuals que vinculen de manera més o menys agradable els consumidors als productors $i$, a través d'aquests, a la totalitat. Els productes adoctrinen i manipulen; promouen una falsa consciència immune a la seua falsedat. I a mesura que aquests productes útils són assequibles a més individus en més classes socials, l'adoctrinament que duen a terme deixa de ser publicitat; es converteixen en manera de vida (Marcuse 1993, 42)

El modus operandi del màrqueting es generalitza i causa un aplanament general de la cultura. Una versió vellutada de l'enginyeria lingüística de 1984 irromp per onsevulla. Ja que "és la paraula que ordena i organitza, que indueix la gent a actuar, comprar i acceptar" (MARCuSE 1993, 116), el llenguatge s'erigeix en un mitjà de control essencial dins de les societats democràtiques. Els discursos públics utilitzen eslògans i frases curtes, facils de recordar, que minimitzen la reflexió i provoquen tranquil.litat en els destinataris. Els conceptes més importants són trivialitzats: la llibertat, els drets, la democràcia, la seguretat, la família, el sofriment, l'èxit, la felicitat són preses propícies de la retòrica.

Hi sobra dir que la democràcia tampoc es deslliura de la propaganda i la manipulació. Els nivells amb els quals influeixen sobre la societat i la llibertat d'informació són graduals. Oscil.la entre la "propaganda blanca" de la publicitat, en la qual "el missatge promocional està clar", fins a la "propaganda negra", basada en la falsificació completa de la realitat i de la història, passant per la "propaganda grisa", on regna una ambigüitat que mostra unes parts mentre n'oculta d'altres, que transforma dubtes en certeses i viceversa (CHIAIs 2008, 161). Les notícies grises tanquen l'apogeu distòpic del control persuasiu perquè aconsegueixen vendre mecanismes autoritaris de mistificació com a processos democràtics. La informació del poder persuasiu no ha de destruir o inventar la veritat necessàriament. Li és suficient intervindre sobre el significat i la percep- 
ció dels esdeveniments, seleccionant els fets i insistint en temes de demostrada apel.lació. Es desinforma, per a informar, igual que en 1984, quan s'“augmenta" la ració setmanal de xocolate de 30 a 20 grams. Les fake news representen un greu problema del discurs sociopolític, cultural i científic de la nostra societat de la postveritat, on la narrativa dels grups d'influència confia més en l'emoció que en fets verificats. Els mass media divulguen deliberadament notícies distorsionades o falses per a dirigir l'opinió pública i exacerbar l'enfrontament polític. Al servei dels interessos dels grups privilegiats, les fake news danyen la governabilitat democràtica global. Donald Trump, per exemple, "mentia quasi cinc vegades al dia en el primer període després de la seua elecció... Al cap d'un any i mig en el càrrec, el nombre va arribar a huit vegades al dia per un total de 4.229 declaracions falses o enganyoses" (Higdon 2020, 5).

En la distopia, per consegüent, tot pot convertir-se en una "eina" del control, inclosa la tecnologia. Quan un medium tecnològic s'afirma, causa canvis en els hàbits socials i de comunicació de les persones, fins a influir en la formació del pensament i de les paraules. Cada nou medium comporta característiques específiques que modifiquen la velocitat, la disponibilitat, la investigació i la interiorització de la cultura, del coneixement i del treball. En aquells que l'utilitzen, estimulen uns certs usos de la intel-ligència i del llenguatge, i influeixen en la manera d'expressar-se i en les relacions entre les parts interessades. Sols cal pensar en la revolució comunicativa representada per la televisió en els anys cinquanta i seixanta o per Internet des del 2000: les distàncies s'han reduït i notícies i informació es fan sempre més accessibles, transformant un món que semblava sense límits en una "aldea global". El major risc que prové d'un ús deformat o extrem de la tecnologia i dels mitjans de comunicació és l'acceptació passiva o a priori de la seua influència. El profund condicionament porta els usuaris a acostumar-se a la presència d'aquestes "extensions" i a convertir-se en "esclaus" (McLuhan 2002, 55). Una prova és la recent obsessió, especialment de les generacions més joves, amb smartphones i social media, que poden atomitzar les relacions socials fins a substituir-les per una comunicació deslocalitzada, simplificada i constant, quasi com en $\mathrm{La}$ màquina s'atura (1908) d'E. M. Forster. En aquesta novel.la de l'autor britànic, la societat, confinada en el subsol i totalment cuidada per "omnipotents" i "eternes" màquines, considera deplorable el contacte físic i es parla sols a través de pantalles, símbols ante litteram d'internet i de les xarxes socials.

La distopia sol connectar poder i tecnologia: "l'Ull i l'Orella de la Policia" que controla l'Estat Mundial de Kallocaïna (1940) de Karin Boye i el Gran Germà de 1984 es reflecteixen, per exemple, en la hipervigilància de la NSA (Agència de Seguretat Nacional dels Estats Units) i en la ingerència dels trolls russos en la política internacional. Tecnologia i media no són neutrals en la 
seua essència, ni tan sols material: impliquen un condicionament dels usuaris i poden ells mateixos convertir-se en missatge. D'aquesta reflexió, la famosa declaració del sociòleg canadenc McLuhan: "The medius is the message":

Tots els mitjans ens estomaquen minuciosament. Són tan penetrants en les seues conseqüències personals, polítiques, econòmiques, estètiques, psicològiques, morals, ètiques i socials, que no deixen cap part de la nostra persona intacta, inalterada, sense modificar (McLuHAN I969, 26)

\section{Anàlogament en Marcuse (1993, 26):}

La tecnologia serveix per a instituir formes de control social i de cohesió social més efectives i més agradables. [...] Davant les característiques totalitàries d'aquesta societat, no pot mantindre's la noció tradicional de la "neutralitat" de la tecnologia. La tecnologia com a tal no pot ser separada de l'ús que se’n fa; la societat tecnològica és un sistema de dominació que opera ja en el concepte i la construcció de tècniques

També en les democràcies els individus no suggestionats per les tècniques de persuasió acaben sent catalogats com antisocials, marginalitzats i perseguits en nom de l'ordre, com els mutants en el món dels X-Men. Hi ha tres grups principals de subjectes "perillosos". En el primer, trobem els enemics declarats del sistema vigent, el cas dels activistes que, durant el G8 de Gènova de 2001, van ser detinguts il.legalment i torturats per la policia, en un acte que, segons Amnistia Internacional, va suposar la "suspensió més greu dels drets democràtics en un país occidental després de la Segona Guerra Mundial". Per als insurgents, les tècniques més punitives de repressió continuen vigents. $\mathrm{Al}$ segon grup hi pertanyen les minories. Els cossos estranys o diferents per raons d'ètnia, religió, sexe, orientació sexual o nivell econòmic són sovint marginats, fins i tot convertits en il.legals, limitant els seus drets de iure o de facto. L'esclavitud i la segregació racial dels afroamericans als Estats Units representen uns dels majors exemples d'aquests processos discriminatoris. El brutal homicidi per asfíxia de l'afroamericà (desarmat) George Floyd a les mans d'un policia de Minneapolis al maig de 2020 i les consegüents protestes que es van estendre pel país confirmen la pervivència del racisme sistèmic (exacerbat per la brutalitat policial) que, després de segles, continua deixant la població negra en una posició subordinada en la societat estatunidenca.

En aquest atac contra l'alteritat també es destaquen les qüestions de gènere perquè el cos femení es converteix en una zona de conflicte patriarcal extremat per un masclisme sistèmic i tòxic. Sovint, les dones acaben passivament 
encadenades a la sexualitat i maternitat, factors que, en les distopies feministes més fosques com l'esmentada El conte de la serventa, Rellotges de sang (2018) de Leni Zumas i Before She Sleeps (2018) de Bina Shah, s'exacerben fins a reemplaçar completament la identitat femenina, fins a aniquilar-la. En canvi, la identitat masculina està activament modelada per mites arquetípics que exalten el poder de l'home i consideren la dona com una mercaderia "que emergeix dels interessos del poder masculí i els serveix" (Elichaoff i Frost 20 i 4, 43). Citant Beauvoir (20 Io, 26): "La Humanitat és mascle, i l'home defineix la dona no en si mateixa, sinó en relació amb ell; no la considera com un ésser autònom”. El gènere és "una estructura social de normes i institucions" que influencia "rols, comportaments i expectatives que s'atribueixen als homes (i als xiquets) i a les dones (i a les xiquetes)" (Lombard i MCMillan 20 i 3, 8). L'extrem resultat de les tendències patriarcals és la violència, que comença desvalorant les dones a través de llenguatge sexista, control i agressió verbal i arriba a violació, abusos i assassinat. Com més conservadora és la societat i profunds són els estereotips, més alta és la incidència de la violència masclista (ReID-CunNingham 2008, 282-4). Segons estimacions de l'OMS (2017), "una de cada tres (35\%) dones han patit violència física i/o sexual de parella o violència sexual per tercers". Tenint també en compte formes afins de violència, com els abusos familiars no de parella i la violència psicològica, el percentatge de dones maltractades creix exponencialment. Segons estimacions de l'UNODC (2019), "un total de 87.000 dones van ser assassinades intencionalment en 2017 [a tot el món]. Més de la meitat d'elles (58\%), és a dir 50.000, van ser assassinades per les seues parelles o altres membres de la família." Això significa que, l'any en qüestió, van morir 238 dones al dia, simplement per ser dones.

En l'últim grup se situen els enemics externs. Quan la Segona Guerra Mundial va acabar, la majoria dels països involucrats van rebutjar la guerra com a solució als conflictes internacionals. La bona voluntat no tardaria a esvair-se. És cert que en territori europeu, des de 1945, no hi ha hagut guerres, excloent el sagnant conflicte de Iugoslàvia. No obstant això, la Unió Europea i els Estats Units van participar i continuen participant en guerres contra terceres nacions o faccions (en particular les de filiació terrorista). Sovint, aquestes han sigut "guerres preventives", rebatejades amb noms enaltidors de la pau i la llibertat, que, en realitat, han causats milions de víctimes civils i, en lloc d'estabilitzar situacions de crisis, han empitjorat les condicions sociopolítiques i les de vida dels ciutadans, com a l'Afganistan i l'Iraq, i han afavorit fins i tot el naixement d'un nou enemic despietat, l'Estat Islàmic.

A més, durant segles, el colonialisme i l'imperialisme van perpetuar violències, repressions i exterminis de poblacions colonitzades, descrivint sovint les seues accions com a actes de civilització. Moltes democràcies, les mateixes 
que es van oposar al nazisme i al feixisme en nom de la llibertat, van demostrar menys respecte als drets quan van haver d'abandonar les seues colònies, com proven les violacions dels drets humans ocorreguts durant l'alliberament d'Algèria. Segons Aimé Césaire (I999), la política de Hitler sembla pitjor només perquè va aplicar al cor d'Europa pràctiques derivades del colonialisme. Aquestes es consideren execrables quan s'apliquen en països "civilitzats" i legítimes quan es dirigeixen contra poblacions "inferiors", com africans, culís, nadius americans, indis, asiàtics, poblacions d'Orient Mitjà, etc. (12).

Com per als esmentats X-Men, les autoritats distòpiques només necessiten una excusa adequada per a transformar l'alteritat en una amenaça i un factor de trauma i crisi. Tots poden ser perseguits per alguna raó: immigrants, afroamericans, musulmans, asiàtics, homosexuals, pobres o dones poden convertir-se en "mutants", en cas de necessitat sociopolítica. La lògica àvida i inclement del benefici del capitalisme és causa d'injustícies, de desigualtats socials i d'explotació econòmica i ecològica. Perquè una part de la població puga gaudir d'una utopia opulenta (i inclinada a l'egoisme), el món neoliberal on vivim permet que una altra part s'ofegue en la misèria, la marginalització, la contaminació, la falta de drets i de garanties, com ens recorden diferents obres distòpiques anticapitalistes. En la sèrie 3\% (2016-2020), per exemple, només el 3\% de la població pot viure a l'illa paradisíaca d'Offshore, mentre que el $97 \%$ està relegat a una favela gegant. Anàlogament, Elysium (2013), pel-lícula de Neill Blomkamp, mostra una Terra pobra, malalta, contaminada i superpoblada, on les classes més humils sobreviuen desesperadament entre fem, òxid i pols. En canvi, l'elit mundial habita feliçment en una idíl.lica estació espacial, saludable, rica i confortable. En Snowpiercer (2013) de Bong Joon-ho, els supervivents a una nova edat de gel viuen en un tren "de moviment etern" que anualment recorre el món, amb la tercera classe oprimida i abusada per la primera per a "mantindre un equilibri sostenible". En la "Màquina Sagrada" que és l'Snowpiercer, cadascú ha de romandre en el seu lloc perquè, segons la Ministra Mason,

[...] l'ordre és la barrera que conté el fred i la mort. Tots cal que, en aquest tren de la vida, romanguem en les estacions assignades. Cadascun de nosaltres ha d'ocupar les posicions particulars preassignades. Es posarien una sabata al cap? Per descomptat que no farien tal cosa. Una sabata no va al cap. Una sabata va en un peu. Al cap, van els barrets. Jo soc un barret i vostés, una sabata

Siga com siga el rerefons, des de l'espai fins al microcosmos del tren que "trenca la neu", la humanitat sembla incapaç d'establir una realitat equitativa i digna per a cada individu. L'ordre distòpic implica prevaricació i 
desigualtat. La societat podria ser justa, però tria la injustícia. Les distopies més dures $\mathrm{i}$ orwel.lianes desborden de despietades guerres, de camps d'extermini, d'individus i pobles privats dels seus drets civils i humans, de dones violades, de venjança, de supremacia racial i de gènere. Huxley ens ensenya, no obstant això, que la distopia no es limita al dolor, la coacció, la punició i la por. Es desenvolupa, igualment, en el patrocini institucional de la felicitat i del plaer, en la cancel-lació de l'alta cultura a l'encalç de l'entreteniment amable, en l'exaltació de la publicitat i del consumisme, en la constant justificació del privilegi i de la disparitat. La distopia no pertany solament a la ciència-ficció. Està continguda en les ambicions del poder i en la submissió i complicitat de les masses. Mostrar "mals llocs" més pròxims del que ens agradaria estimula la reflexió sobre el vertader estat de les nostres democràcies i promou la participació sociopolítica de la població. És vital apreciar com la distopia literària i cinematogràfica evoca la caixa de Pandora: no sols guarda els mals del món, sinó també l'esperança. Al cap i a la fi, ens conta històries de rebel.lió i desobediència. Fins i tot les obres amb final tràgic, ens espenten a quelcom utòpic: a la resistència.

Traduït per MARISA SERRA 


\section{BIBLIOGRAFIA}

Arciero, A. 2005, Orwell: contro il totalitarismo e per un socialismo democratico, Milà: Franco Angeli.

Arendt, H. 1962, The Origins of Totalitarianism, Cleveland: Meridian Books.

Atwood, M. 2007, Il Racconto dell'Ancella, Milà: Tea.

Austin, J. L. 1975, How to Do Things with Words, Cambridge: Harvard University Press.

Baccolini, R. i Moylan, T. (ed.) 2003, Dark Horizons. Science Fiction and the Dystopian Imagination, Nova York-Londres: Routledge.

Battaglia, B. I998, Nostalgia e mito nella distopia inglese, Ravenna: Longo.

Bernays, E. I947, "The Engineering of Consent", The Annals of the American Academy of Political and Social Science, 270 (1): 113-20.

Booker, M. K. I994, Dystopian Literature. A Theory and Research Guide, Westport: Greenwood Press.

Boye, K. I993, Kallocaina, Milà: Iperborea.

Burdekin, K. I985, Swastika Night, Nova York: Feminist Press.

CÉsaire, A. I999, Discorso sul Colonialismo, Roma: Lilith.

Chiais, M. 2008, Menzogna e propaganda: armi di disinformazione di massa, Milà: Lupetti.

Chomsкy, N. 20 i i, Media Control. The Spectacular Achievements of Propaganda, Nova York: Seven Stories Press.

Colombo, A. I987, Utopia e Distopia, Milà: Franco Angeli.

Courtois, S. I998, Il Libro Nero del Comunismo, Milà: Mondadori.

Dalcher, C. 2018, Vox, Milà: Nord.

De Beauvoir, S. 20io, The Second Sex, Nova York: Vintage Books.

Di Minico, E. 2018, Il futuro in bilico, Milà: Meltemi.

Elichaoff, F. i Frost, N. 2014, "Feminist Postmodernism, Poststructuralism, and Critical Theory", Feminist Research Practice: A Primer, Hesse-Biber, S. (ed.), Thousands Oaks: Sage Publications.

Fernández Buey, F. 2007, Utopias e ilusiones naturales, Barcelona: El Viejo Topo. Fimiani, E. 2004, "I linguaggi politici del Fascismo ai tempi dei plebisciti", Propaganda e comunicazione politica, Ridolfi, M. (ed.), Milà: Mondadori.

Forster, E. M. 2020, La macchina si ferma, Milà: Mondadori.

Foucault, M. 2004, La Volontà di Sapere. Storia della Sessualità 1, Milà: Feltrinelli. Foucault, M. I993, Sorvegliare e punire, Torí: Einaudi.

Gentile, E. 2007, Le religioni della politica. Fra democrazie e totalitarismi, Bari: Laterza.

Goldblatt, P. I999, "Reconstructing Margaret Atwood's Protagonists", World Literature Today, 73 (2): 275-82. 
Higdon, N. 2020, The Anatomy of Fake News, Berkeley: University of California Press.

Huxley, A. 2009, Mondo Nuovo. Ritorno a Mondo Nuovo, Milà: Mondadori.

Inderbitzin, M. L., et al. 20 I2, Deviance and Social Control. A Sociological Perspective, Londres: Sage Publication.

IPSOS 2019, "Ciak Migraction: Indagine sulla percezione dei migranti in Italia",

19 Ottobre, https://www.ipsos.com/it-it/ciak-migraction-indagine-sulla-percezione-del-fenomeno-migratorio-italia

Knight, D. 20 i I, Hell's Pavement, Londres: Hachette UK.

Kumar, K. I99I, Utopia and Anti-Utopia in Modern Times, Oxford: Blackwell.

Le Bon, G. 200I, The Crowd. A Study of the Popular Mind, Kitchener: Batoche Books, (ebook).

Lippmann, W. I998, Public Opinion, Nova Brunswick: Transaction Publishers.

Lombard, N. i McMillan, L. 20 13, Violence Against Women. Current Theory and Practice in Domestic Abuse, Sexual Violence, and Exploitation, Londres: Jessica Kingsley Publishers.

Maltone, C. 20 i I, "L'immigrazione nei media italiani. Disinformazione, stereotipi e innovazioni”, Line@editoriale n.3.

Manferlotti, S. i984, Antiutopia: Huxley, Orwell, Burgess, Palerm: Sellerio.

Marcuse, H. I993, El hombre unidimensional, Barcelona: Planeta De Agostini.

McKay, G. I996, "Katharine Burdekin: An Alien Presence in Her Own Time", Recharting the Thirties, Quinn, P. J. (ed.), Londres: Associated University Presses.

McLuhan, M. 2002, Gli strumenti del comunicare, Milà: NET, Milano.

McLuhan, M. 1969, El medio es el masaje, Buenos Aires: Editorial Paidós.

Moore, A. i Lloyd, D. 2006, Vper Vendetta, Roma: Magic Press.

Mosse, G. 2007, Le Guerre Mondiali. Dalla tragedia al Mito dei Caduti, Roma: Laterza.

Mosse, G. 2007, La Nazionalizzazione delle Masse, Bolonya: Il Mulino.

OMS 2017, "Violencia contra la mujer", November 29, https://www.who.int/es/ news-room/fact-sheets/detail/violence-against-women

Orwell, G. 2020, 1984, Madrid: Verbum.

OSCE 2019, "Hate Crime Reporting. 2018 Hate Crime Data", November 19, https://hatecrime.osce.org/infocus/2018-hate-crime-data-now-available

Packard, V. 2007, The Hidden Persuaders, Nova York: IG Publishing.

Panattoni, R. 2002, Storia del romanzo, Milà: Alpha Test.

Pohl, F. i Kornbluth, C. M. 2008, Mercaderes del espacio, Barcelona: Ediciones Minotauro.

Postman, N. 2005, Amusing Ourselves to Death, Nova York: Penguin Books.

ReIch, W. I977, La psicologia di massa del Fascismo, Milà: Mondadori (ebook). 
Reid-Cunningham, A. 2008, "Rape as a Weapon of Genocide", Genocide Studies and Prevention 3 (3): 279-96.

Rushin, S. i Griffin, S. E. 20i 8, “The Effect of President Trump's Election on Hate Crimes”, SSRN Electronic Journal, January 14, https://papers.ssrn.com/ sol3/papers.cfm?abstract id $=3102652$

Russell, E. I99I, "The loss of the feminine principle in Charlotte Haldane's Man's World and Katharine Burdekin's Swastika Night", Where no man has gone before: Women and Science Fiction, Armitt , L. (ed.), Londres-Nova York: Routledge.

SARgent, L. T. I975, "Utopia: The Problem of Definition”, Extrapolation 16 (2): 137-48.

SCArry, E. I990, La sofferenza del corpo, Bolonya: Il Mulino.

Schmitt, C. 2007, The Concept of the Political, Chicago: University of Chicago Press.

Sнaн, B. 20 1 8, Before She Sleeps, Harrison: Delphinium Books.

UNODC 2019, Gender Studies on Homicide. Gender-related Killing of Women and

Girls, Vienna: Division for Policy Analysis and Public Affairs - United Nations Office on Drugs and Crime.

Volkoff, V. 2006, Le montage, París: Pocket.

Zamiatin, Y. 2007, Noi, Milà: Lupetti.

Zimbardo, P. 20 i i, The Lucifer Effect. How Good People Turn Evil, Nova York: Random House.

Zumas, L. 20 1 8, Relojes de sangre, Barcelona: Ediciones Destino.

Pel-LÍCUles I SÈrieS

Aguilera, P. 2016-2020, 3\%, Netflix.

Anderson, M. 1976, La fuga de Logan, Metro-Goldwyn-Mayer.

Blomkamp, N. 2013, Elysium, Warner Bros.

Bong, J. 201 3, Snowpiercer, The Weinstein Company.

Carpenter, J. I988, Están vivos, Universal Pictures.

Fukunaga, C. 2018, Maniac, Netflix.

LuCAs, G. I97 I, THX 1138, Warner Bros. 